\title{
Age-related changes in the colonic blood supply: their relevance to ischaemic colitis
}

\author{
J. C. BINNS AND P. ISAACSON ${ }^{1}$ \\ From the Department of Pathology, Faculty of Medicine, Southampton University Hospital, Southampton
}

SUMMARY Ischaemic colitis due to non-occlusive mesenteric ischaemia is a disease of the elderly which commonly involves the left side of the colon; selective splenic flexure involvement is said to be especially common. In an attempt to explain these features postmortem angiograms were performed on the superior and inferior mesenteric arteries of 37 postmortem subjects. A distinct agerelated tortuosity of the long colic arteries was noted which could account for the increasing incidence of ischaemic colitis with age. No anatomical basis for the higher incidence of left-sided involvement was found and, specifically, no critical point in the arterial circulation at the splenic flexure was demonstrated.

Ischaemic colitis is a term introduced by Marston in 1966 to describe all degrees of ischaemic injury of the colon ranging from superficial mucosal necrosis to full-thickness infarction. Ischaemia of the colon may follow occlusion of the large or small vessels which supply that organ but in many cases of ischaemic colitis there is no demonstrable blood vessel occlusion (Renton, 1972). These cases of nonocclusive mesenteric ischaemia are thought to be caused by low flow states in the splanchnic circulation, often following a hypotensive episode (Renton, 1972; Aldrete et al., 1977). Characteristically, this type of intestinal ischaemia occurs in older, often debilitated, patients, many of whom have chronic cardiac disease and may be taking digitalis preparations. The left side of the colon is said to be more frequently involved in ischaemic colitis and the splenic flexure is regarded as being the area most at risk (Marcuson, 1972; British Medical Journal, 1977).

Hypotensive episodes, while undoubtedly more common in older patients, are not the prerogative of the elderly, yet intestinal ischaemia following a hypotensive event is extremely rare in young patients, only four such cases having been described in the literature (Carey et al., 1967; Renton, 1967; Rickert et al., 1973; Turnbull and Isaacson, 1977). Using postmortem angiographs we have studied the anatomy of the colonic circulation over a wide

${ }^{1}$ Address for reprints: P. Isaacson, Department of Pathology, Southampton General Hospital, Southampton SO9 4XY.

Received for publication 1 December 1977 age range in an attempt to explain this discrepancy and to account for the reports of the high incidence of splenic flexure and left-sided involvement. The study showed that a distinctive age-related change occurs in the entire colonic circulation which could account for the age distribution of ischaemic colitis. The concept of a critical point or 'watershed' area in the circulation at the splenic flexure was not supported and we could find no anatomical reason for a greater incidence of left-sided disease.

\section{Methods}

Thirty-seven subjects were selected from routine hospital necropsies to include a wide age range (new-born to 92 years). There were 18 females and 19 males. Complete evisceration of internal organs was performed with division of the rectum as low as possible and the viscera were laid out to expose their posterior aspect. The aorta was then opened posteriorly and the degree of atheroma graded subjectively on a + to +++ scale. Particular attention was paid to the ostium of the inferior mesenteric artery (IMA), as this is often narrowed or occluded.

Injection of radio-opaque material into the superior mesenteric artery (SMA) (29 subjects) or IMA (eight subjects) was then carried out using a modification of the technique described by Reiner et al. (1959). The injection material used was $100 \%$ barium sulphate suspension ${ }^{2}$ mixed with an equal volume of

${ }^{2}$ Micropaque, Nicholas Laboratories Ltd. 
water. This mixture was contained in a reservoir attached to a sphygmomanometer pump and delivery of the Micropaque into the relevant artery was via a plastic tube attached to a cannula which was tied or clamped into the artery. Pressure was gradually increased to $200 \mathrm{~mm}$ mercury and this was maintained for 10 minutes. After injection, the colon was dissected from the other viscera together with as much attached mesentery as possible in an attempt to include the marginal artery. The colon was then laid out, following its normal anatomy, over an $x$-ray film ${ }^{3}$ and a marker placed at the splenic flexure. A Faxitron radiograph machine ${ }^{4}$ was used with automatic exposure at $30 \mathrm{Kv}$. After radiography the colon was opened and inspected for any relevant pathology and sections for histology were taken from a representative sample of the colons to determine the extent to which the Micropaque filled the vasculature.

In analysing the radiographs the extent to which the colonic arterial supply was filled was noted. The characteristics of the arterial supply of the ascending colon, transverse colon, splenic flexure $(5 \mathrm{~cm}$ on either side of the marker) and descending colon were examined and recorded separately. Particular attention was paid to the marginal artery and continuity was recorded only if the vessel could be seen extending from the caecum to the sigmoid. Where the artery had been torn in removal its continuity was recorded as questionable. The diameter of the marginal artery was measured using calipers and an average of five measurements for each segment of the colon was recorded.

A minimum of five long colic arteries (those arteries branching from the marginal artery to the colon (Fig. 4) in each segment of the colon where they were well visualised was examined in the following way. The radiograph was projected onto a screen to obtain a magnification of $\times 7$. A copper wire was then bent to follow the course of the artery from its origin to its disappearance. The ratio of the length of the straightened wire to the straight line distance the artery had travelled was used to express tortuosity (T). Average tortuosity of the five arteries for each segment of the colon was plotted against patient age (Fig. 1). Regression ( $r$ ) coefficient values for the best straight line of $T$ plotted against age were calculated. From the $r$ values, values for $t$ (Student's $t$ test) and probability (P) were obtained.

\section{Results}

After some variability in the initial specimens the arterial supply of the colon could be reliably

${ }^{3}$ Kodirex, Kodak Ltd.

${ }^{4}$ Hewlett Packard. filled. Histological sections showed barium sulphate in the submucosal plexus but not beyond and there was no venous filling.

SMA INJECTIONS (Fig. 2)

In 23 of 29 injections good filling of the colonic circulation was obtained from caecum to rectum. In two colons filling was only to the splenic flexure and in four cases filling was generally poor. These were colons injected early in the study before an entirely reliable technique was established. In 13 cases of occlusion or severe stenosis of the IMA ostium complete filling of the colonic circulation was obtained in nine. The four other cases were those already referred to, which were examined early in the study. One case of non-occlusive ischaemic colitis involving the transverse colon was included in the study in which SMA injection resulted in good filling of the entire colon.

IMA INJECTIONS (Fig. 3)

Of eight IMA injections good filling of the colonic circulation from caecum to rectum was noted in five. In one colon there was good filling to the splenic flexure only and in two subjects there was poor filling of the inferior mesenteric artery. In one of these the artery was compressed by a mass of lymph nodes containing metastatic bronchogenic carcinoma.

\section{MARGINAL ARTERY}

The diameter of the marginal artery decreased from right to left. Average diameters of the artery at the ascending colon, transverse colon, splenic flexure and descending colon were $1.6 \mathrm{~mm}, 1.13 \mathrm{~mm}$, $0.94 \mathrm{~mm}$, and $0.89 \mathrm{~mm}$ respectively. In adults the diameters were constant over the wide range of ages. In 17 of 37 colons the artery was continuous and, specifically, no interruption or unusual narrowing was seen at the splenic flexure (Figs. 1, 2, 3, 4). In a further 11 colons the artery had been damaged during removal of the colon but it appeared to be continuous. In these colons, again, no change in the artery was noted at the splenic flexure. In three colons the artery filled to the splenic flexure only (two SMA injections and one IMA injection) and the entire artery was poorly visualised in six. Of these, five were early studies which were probably technically inadequate and one was caused by compression of the IMA by metastatic tumour.

\section{LONG COLIC ARTERIES}

In young subjects these vessels were straight with almost complete absence of tortuosity (Figs 4, 5). Regression lines calculated from the graphs plotting tortuosity against age indicated that tortuosity of these vessels increases significantly with age (Figs 

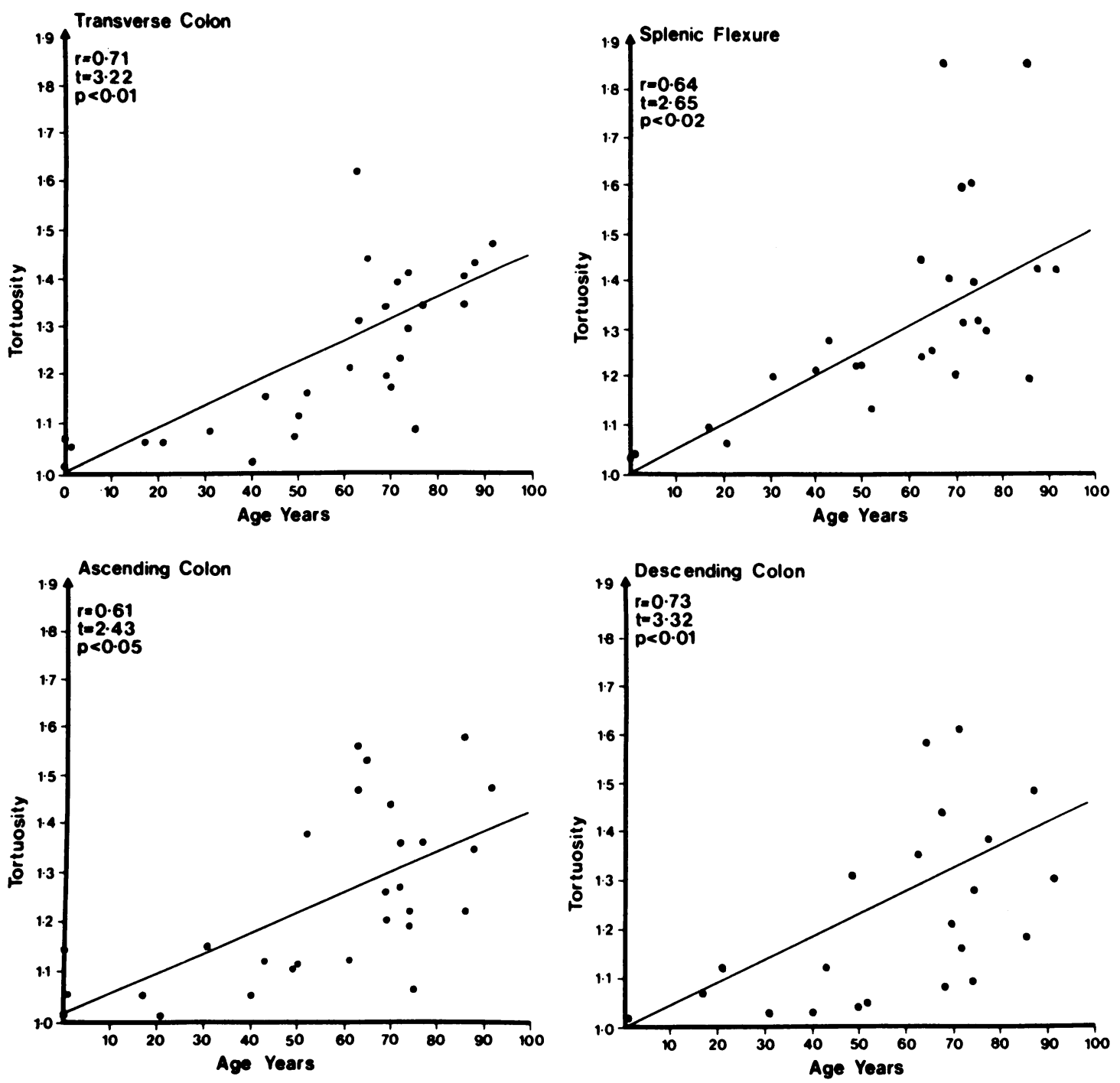

Fig. 1 Tortuosity of long colic arteries plotted against age for different segments of the colon.

$1,4,5)$. No significant difference was noted in tortuosity of the long colic arteries in the different segments of the colon. Given that the severity of atheroma usually increases with age, it is not surprising that the degree of tortuosity correlated roughly with the subjective grading of aortic atheroma. However, in individual young subjects with unusually severe atheroma tortuosity was no greater than expected for age and similarly for old subjects with unusually mild atheroma tortuosity was nevertheless severe. Counts made of the number of long colic arteries per unit length of colon showed no change with age.

\section{Discussion}

We have demonstrated a distinctive age-related change in the colonic circulation. In non-occlusive mesenteric ischaemia increased arterial tortuosity may contribute to mucosal ischaemia by providing increased resistance to blood flow. When fluid flows through a bend in a vessel a secondary flow is set up due to the centrifugal force associated with motion on a curve. The combination of primary and secondary flow gives the blood a double helical motion and extra energy (pressure) is necessary to maintain the increased movement of fluid which 


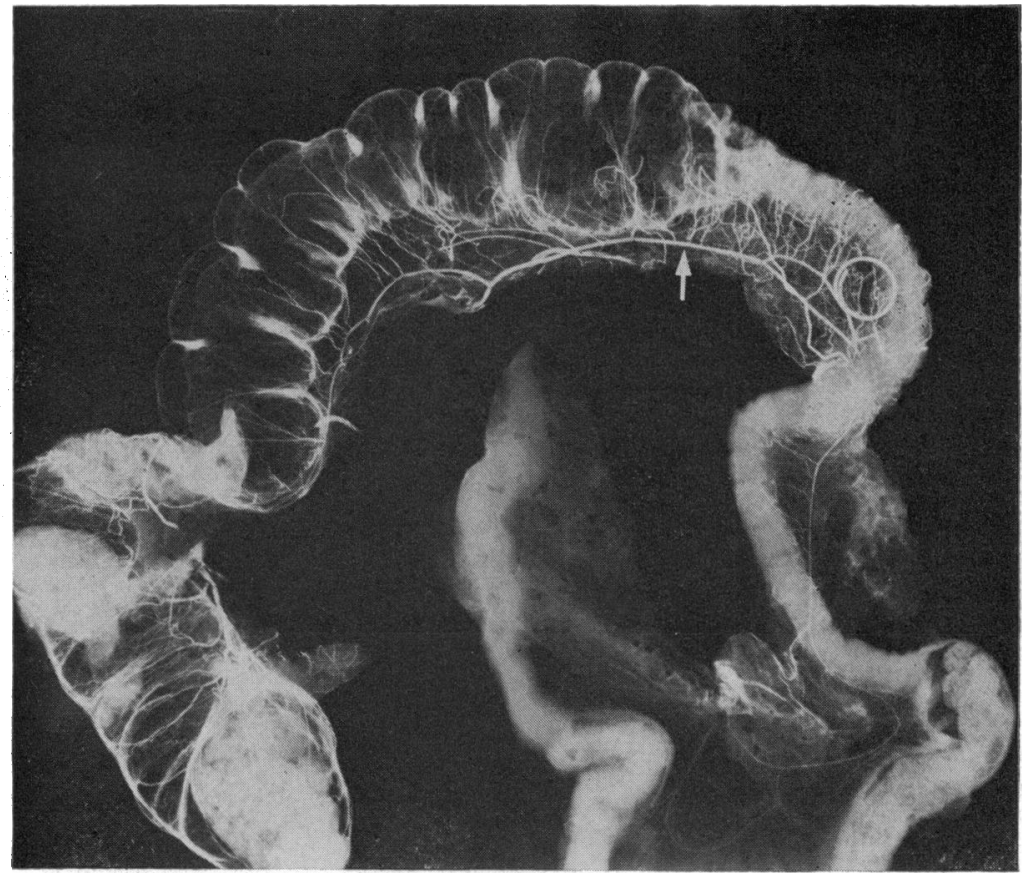

Fig. 2 Superior mesenteric artery injection in a 49 year old woman. There is good filling of the entire arterial circulation. The small arrow points to the marginal artery. The splenic flexure is marked by a metal ring.

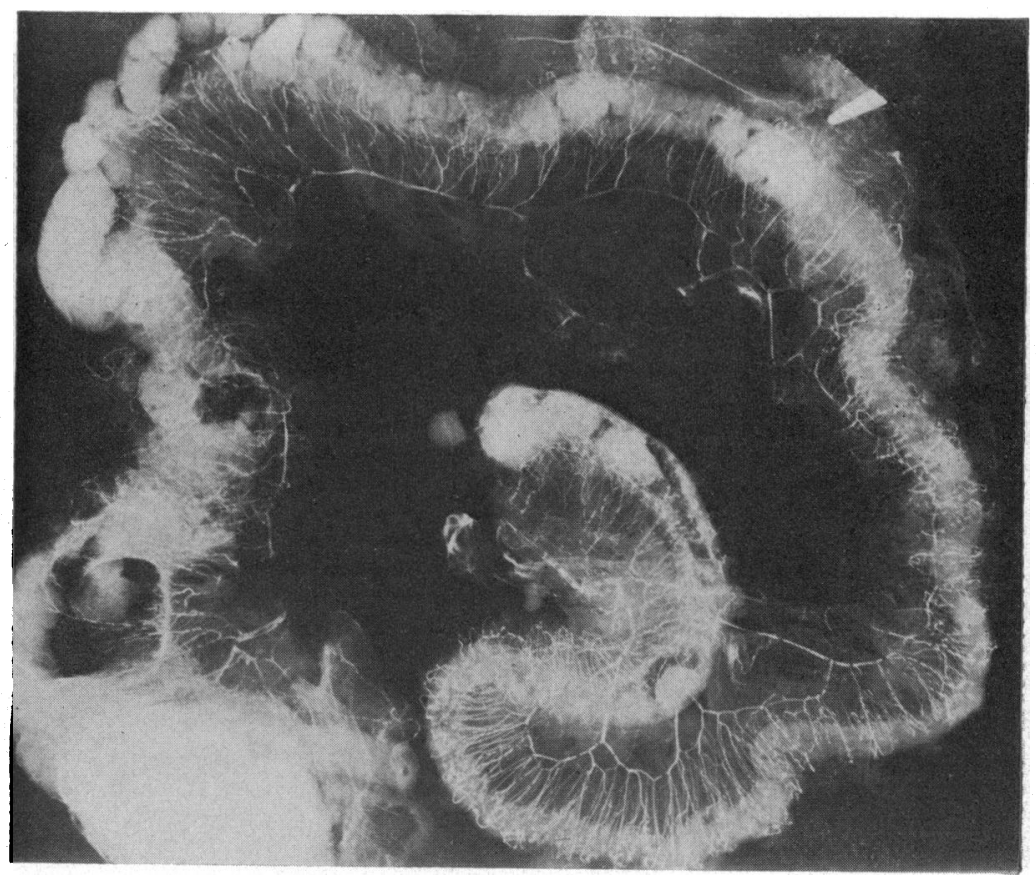

Fig. 3 Inferior mesenteric artery injection in a 52 year old man. There is filling of the entire arterial circulation. The radio-opaque pointer marks the splenic flexure. 


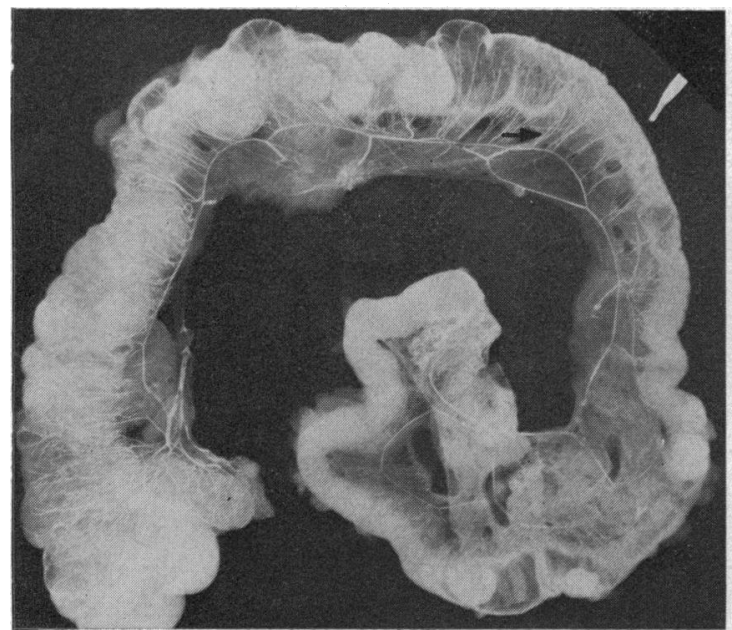

(a)

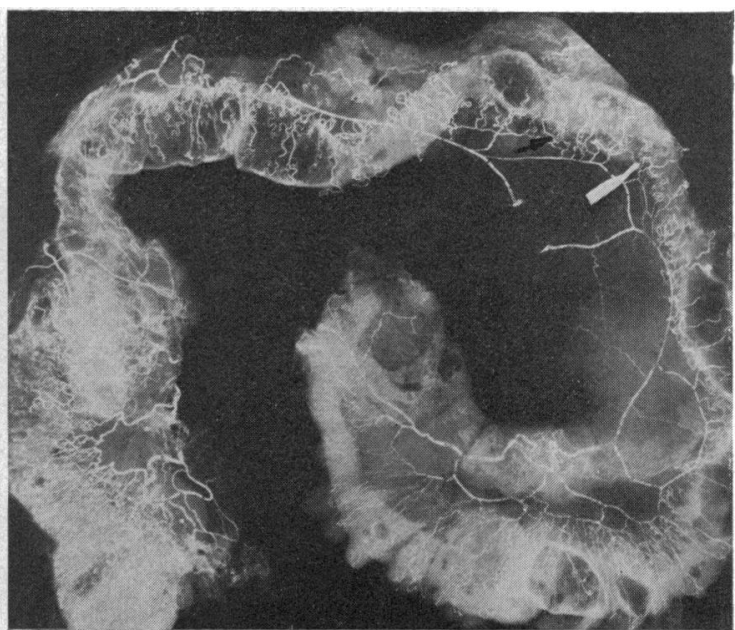

(b)

Fig. 4 Superior mesenteric artery injection in a 20 year old woman (a) and a 92 year old woman $(b)$. There is marked tortuosity of the long colic arteries (small arrow) in (b) as compared with those in (a). The thick pointer indicates the splenic flexure.

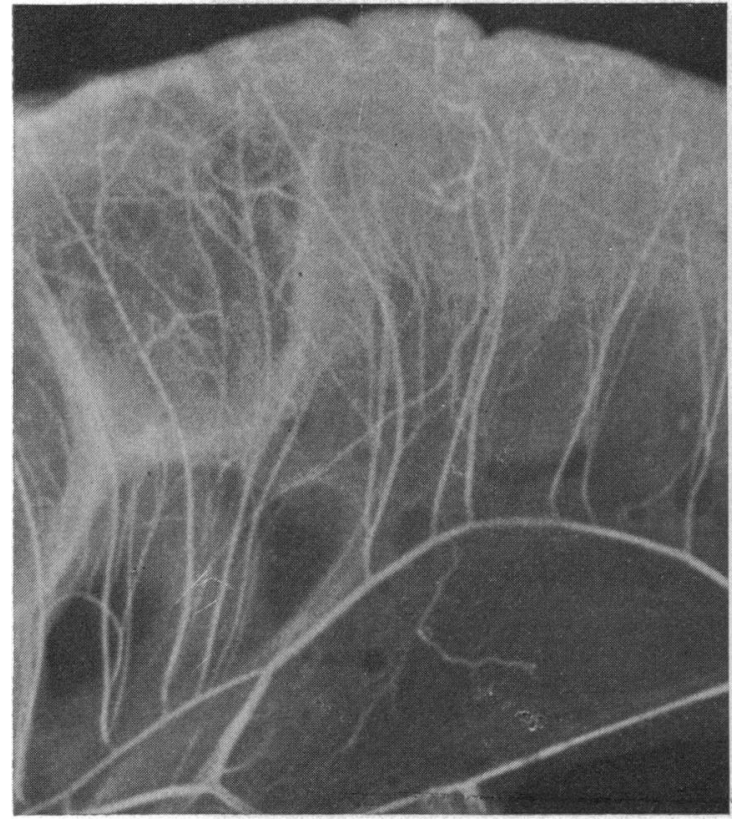

(a)

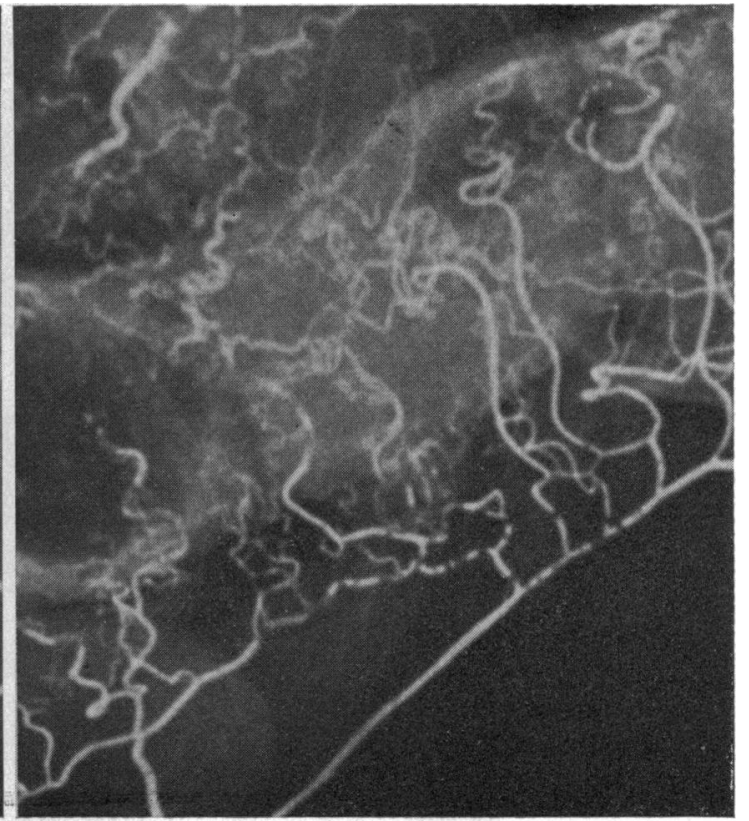

(b)

Fig. 5 Detail of long colic arteries in Fig. $4 a$ and $b$ to show the tortuosity which increases with age. 
does not contribute to forward flow (Brech and Bellhouse, 1973). Therefore, in subjects with markedly tortuous arteries, the effect of a low flow state in the splanchnic circulation would be more likely to result in mucosal ischaemia than in those subjects with straight arteries. This could account for the increasing incidence of ischaemic colitis with age and the great rarity of this disorder in the young, even following severe hypotensive episodes. A morphological basis for the age-related tortuosity is to be expected and histological studies of the small branches of the mesenteric arteries have revealed lesions which progress with age. Arosemena and Edwards (1967) demonstrated lesions in the media of these arteries which included thinning, elastosis and structural disarray, calcification and hypertrophy, all of which could contribute to increased tortuosity.

Our inability to demonstrate a critical point in the colonic circulation at the splenic flexure has led us to examine in some detail the reported frequency of splenic flexure involvement in ischaemic colitis. Marston et al. (1966) was the first to record the special predisposition of the splenic flexure to ischaemia. In his series of 15 cases, 12 had splenic flexure involvement. Similarly, in a large series of 89 cases (Boley and Schwartz, 1971) splenic flexure involvement was noted in 30 . However, splenic flexure involvement alone-that is, without significant extension proximally or distally-was present in only four of Marston's cases and in 10 of the cases reported by Boley. More recent reports of ischaemic colitis lay less stress on the splenic flexure. Of the 14 cases reported by Kaminski et al. (1973) none involved the splenic flexure alone and in the two cases in which it was involved almost the entire colon was ischaemic. In a recent series of 18 cases, Hagihara et al. (1975) likewise include none in which ischaemia was localised to the splenic flexure, although in 10 cases it was involved as part of more extensive disease. The predilection of ischaemic colitis for the splenic flexure has been attributed to the peculiar anatomy of the arterial circulation in this region as described by Griffiths in 1956. Griffiths maintained that 'a truly critical point (in the arterial circulation) exists at the splenic flexure where the marginal artery is often small'. No measurements are given and we are not told the percentage of cases in which the artery was small. In our study the average marginal artery diameter became smaller as the artery progressed from right to left but the diameter at the splenic flexure did not suddenly change and the artery was larger at the splenic flexure than along the descending colon. With the exception of three cases, where filling of colonic arteries did indeed stop at the splenic flexure, we found little evidence for a 'watershed' in this region. Injection of the SMA or IMA usually resulted in adequate filling of the entire arterial circulation of the colon. It is of interest that Griffiths(1966) described a second weak point in the colonic circulation at the caecum and states '... from the anatomical point of view the areas most likely to be damaged due to ischaemic episodes or occlusion of the colic vessels are in the splenic flexure or in the region of the caecum'. Perhaps because of the rarity of caecal ischaemia, Griffiths is rarely quoted in full. We feel there is no firm anatomical basis for the concept that the splenic flexure is at special risk in ischaemic colitis.

There is little doubt that ischaemic colitis more commonly involves the left side of the colon than the right. This is borne out by the series of cases reported by Marston et al. (1966), Boley and Schwartz (1969), Kaminski et al. (1973), and Hagihara et al. (1975), all of which show marked predilection of the disease for the left colon. There is nothing in our study to account for this. Other factors operative in ischaemic colitis, such as intralumenal pressure (Boley et al., 1969), may be of importance in determining the high incidence of left-sided involvement.

\section{References}

Aldrete, J. S., Han, S. Y., Laws, H. L., and Kirklin, J. W. (1977). Intestinal infarction complicating low cardiac output states. Surgery, Gynecology, and Obstetrics, 144, 371375.

Arosemena, E., and Edwards, J. E. (1967). Lesions of the small mesenteric arteries underlying intestinal infarction. Geriatrics, 22 (Jan.), 122-138.

Boley, S. J., Agrawal, G. P., Warren, A. R., Veith, F. J., Levowitz, B. S., Treiber, W., Dougherty, J., Schwartz, S. S., and Gliedman, M. L. (1969). Pathophysiologic effects of bowel distention on intestinal blood flow. American Journal of Surgery, 117, 228-234.

Boley, S. J., and Schwartz, S. S. (1971). Colonic ischemia: Reversible ischemic lesion. In Vascular Disorders of the Intestine, pp. 579-596. Edited by S. J. Boley, S. S. Schwartz, and L. F. Williams, Jr. Appleton-Century-Crofts: New York.

Brech, R., and Bellhouse, B. J. (1973). Flow in branching vessels. Cardiovascular Research, 7, 593-600.

British Medical Journal (1977). Gut ischaemia. Editorial. British Medical Journal, 1, 1557-1558.

Carey, J. S., Okada, F., Monson, D. O., Yao, S. T., and Shoemaker, W. C. (1967). Intestinal infarction in shock with survival after resection. Journal of the American Medical Association, 199, 422-425.

Griffiths, J. D. (1956). Surgical anatomy of the blood supply of the distal colon. Annals of the Royal College of Surgeons, 19, 241-256.

Griffiths, J. D. (1966). Ischaemic diseases of the colon. The blood supply of the colon. Proceedings of the Royal Society of Medicine, 59, 881-882.

Hagihara, P. F., Parker, J. C., and Griffen, W. O., Jr. (1975). Spontaneous ischemic colitis. Diseases of Colon and Rectum, 20, 236-251. 
Kaminski, D. L., Keltner, R. M., and Willman, V. L. (1973). Ischemic colitis. Archives of Surgery, 106, 558-563.

Marcuson, R. W. (1972) Ischaemic colitis. Clinics in Gastroenterology, 1, 745-763.

Marston, A., Pheils, M. T., Thomas, M. L., and Morson, B. C. (1966). Ischaemic colitis. Gut, 7, 1-15.

Reiner, L., Rodriguez, F. L., Platt, R., and Schlesinger, M. J. (1959). Injection studies on the mesenteric arterial circulation. I. Technique and observations on collaterals. Surgery, 45, 820-833.
Renton, C. J. C. (1967). Massive intestinal infarction following multiple injury. British Journal of Surgery, 54, 399-401.

Renton, C. J. C. (1972). Non-occlusive intestinal infarction. Clinics in Gastroenterology, 1, 655-673.

Rickert, R. R., Johnson, R. G., and Wignarajan, K. R. (1973). Ischemic colitis in a young adult patient. Diseases of Colon and Rectum, 17, 112-116.

Turnbull, A. R., and Isaacson, P. (1977). Ischaemic colitis and drug abuse. British Medical Journal, 2, 1000.

\section{The April 1978 Issue}

\section{THE APRIL 1978 ISSUE CONTAINS THE FOLLOWING PAPERS}

Significance of anergy to dinitrochlorobenzene (DCNB) in inflammatory bowel disease: family and postoperative studies S. MEYERS, D. B. SACHUR, R. N. TAUB, AND H. D. JANOWITZ

Further evidence of a primary mucosal defect in coeliac disease H. J. CORNELL AND C. J. ROLLES

Immunocytochemical study of the interaction of soybean trypsin inhibitor with rat intestinal mucosa PATRICIA A. WILSON, R. N. MELMED, MAGDOLNA M. V. HAMPE, AND S. J. HOLT

Vitamin D-3 intestinal absorption in vivo: influence of fatty acids, bile salts, and perfusate $\mathrm{pH}$ on absorption D. HOLLANDER, K. S. MURALIDHARA, AND ALICIA ZIMMERMAN

Absence of $K$ cells in human gut mucosa $R$. CLANCY AND ALESSANDRA PUCCI

Effects of a protein meal, intraduodenal $\mathrm{HCl}$, and oleic acid on portal and peripheral venous secretin and on pancreatic bicarbonate secretion G. BODEN, R. M. WILSON, N. ESSA-KOUMAR, AND O. E. OWEN

Pathophysiological responses to meals in the Zollinger-Ellison syndrome: 1. Paradoxical postprandial inhibition of gastric secretion J. R. MALAGELADA

Abnormal vitamin $\mathbf{D}$ metabolism in cirrhosis R. T. JUNG, M. DAVIE, J. O. HUNTER, T. M. CHALMERS, AND D. E. M. LAWSON

Serum and tumour ferritins in primary liver cancer M. C. KEW, J. D. TORRANCE, D. DERMAN, M. SIMON, G. M. MACNAB, R. W. CHARLTON, AND T. H. BOTHWELL
Effect of ioglycamide (Biligram) on bile flow and biliary lipid secretion in man G. D. BELL, J. DORAN, M. FAYADH, G. MURPHY, AND R. H. DOWLING

Lymphocyte cytotoxicity in chronic active hepatitis: effect of therapy and correlations with clinical and histological changes A. M. G. COCHRANE, A. MOUSSOUROS, A. SMITH, B. PORTMANN, A. L. W. F. EDDLESTON, AND ROGER WILLIAMS

Inhibition by somatostatin (growth-hormone releaseinhibiting hormone, GH-RIH) of gastric acid and pepsin and G-cell release of gastrin A. A. J. BARROS D'SA, S. R. BLOOM, AND J. H. BARON

Intestinal phase of gastric secretion in patients with duodenal ulcer S. J. KONTUREK, N. KWIECIEN, W. OBTULOWICZ, E. SITO, AND J. OLEKSY

Secretion of intrinsic factor and hydrochloric acid after 12 weeks' treatment with cimetidine 0 . EPSTEIN, J. JUDELMAN, G. BEVAN AND S. ARDEMAN

Serum carbenoxolone in patients with gastric and duodenal ulcer J. H. BARON, R. J. N. GRIBBLE, C. RHODES, AND P. A. WRIGHT

Induction of gastro-oesphageal reflux by alcohol S. E. KAUFMAN AND M. D. KAYE

Notes and activities

Book Reviews

Copies are still available and may be obtained from the PUBLISHING MANAGER, BRITISH MEDICAL ASSOCIATION, TAVISTOCK SQUARE, WC1H 9JR, price $£ 2.75$, including postage 